Part of Journal of Research of the National Bureau of Standards, Volume 21, December 1938

\title{
PROPERTIES OF PURIFIED NORMAL HEPTANE AND ISOOCTANE (2,2,4-TRIMETHYLPENTANE)
}

\author{
By Donald B. Brooks
}

\section{ABSTRACT}

Normal heptane and "isooctane" (2,2,4-trimethylpentane) are used universally as the primary standard reference fuels for the knock rating of automotive engine fuels. In developing specifications for these standards, it became apparent that data were needed on the physical properties of samples of the highest possible purity. Material already of high purity was carefully fractionated through columns having an efficiency equivalent to that of 60 theoretical plates. The important properties of the purest fractions obtained thereby were accurately measured. In each case the freezing point of the best material obtained was higher than currently accepted values.

\section{CONTENTS}

I. Origin of investigation -187

II. Source and preparation of materials

III. Test apparatus

IV. Physical properties

V. Calculation of purity .

VI. References_... 852

\section{ORIGIN OF INVESTIGATION}

In 1934 the Cooperative Fuel Research Committee (CFR), representing the automotive and petroleum industries, requested the National Bureau of Standards to develop specifications for $n$-heptane and for "isooctane" (2,2,4-trimethylpentane) which are used as primary standard reference fuels for the knock rating of automotive engine fuels. The investigation of the impurities in the isooctane has been described in this Journal [1]. ${ }^{1}$ A similar investigation on $n$ heptane is in progress. In addition to knowing the nature and properties of the impurities in the standards, it is necessary to know accurately certain properties of $n$-heptane and isooctane of high purity. To this end the purest available materials were further purified, and the boiling points, freezing points, refractive indices, densities, and certain of their differential coefficients were accurately measured on the resulting materials.

\section{SOURCE AND PREPARATION OF MATERIALS}

About 7.6 liters of isooctane of high purity had been obtained in the course of the investigation mentioned above. This material was now distilled through fractionating columns packed with locket chain

\footnotetext{
1 Figures in brackets indicate the references at the end of this paper.
} 
and having an efficiency equivalent to that of 60 theoretical plates. The forerun $(10 \%)$ and residue $(9 \%)$ were discarded and the remaining 81 percent was divided into three roughly equal portions. The boiling points of the individual fractions and the freezing points of the three portions are shown in figure 1.

The center portion of 2,100 and $500 \mathrm{ml}$ of the third portion were combined and again fractionated. The distillate was separated into 10 fractions and the normal boiling point and freezing point of each fraction were measured accurately. The purer fractions were selected for further study.

The source material chosen for the purified $n$-heptane was the purest commercially available material which had been produced at the time this work was done, namely, batch 7 of CFR certified $n$-heptane. About 2.8 liters of this $n$-heptane was fractionated through the columns previously used for the isooctane, and cut into $200-\mathrm{ml}$ fractions. The purer fractions were selected for further investigation.

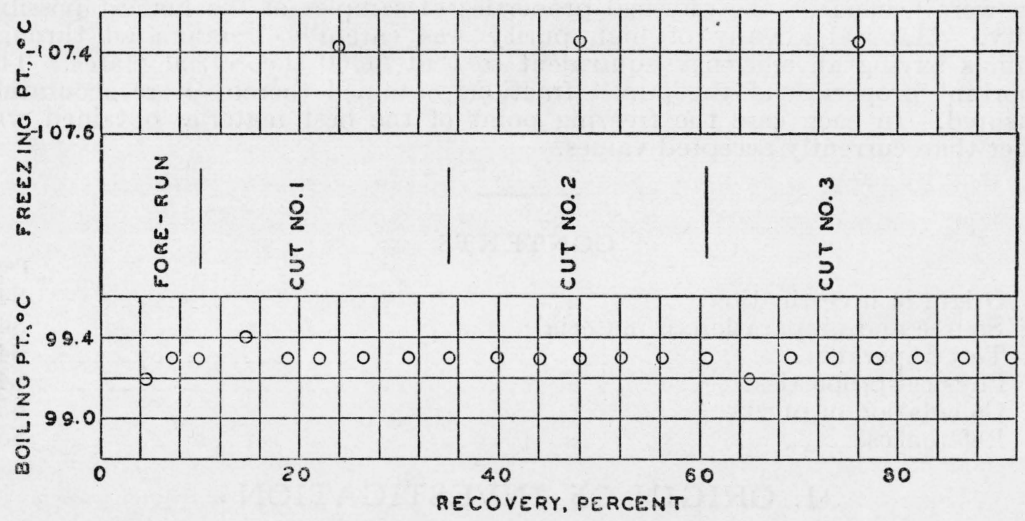

FIgURe 1.-Boiling- and freezing-points of material obtained after first stage of purification of isooctane.

\section{TEST APPARATUS}

The apparatus used in the freezing-point measurements comprised a Pyrex tube containing a platinum resistance thermometer and stirrer, this tube being surrounded to a point above the sample height by a metal tube covered with aluminum foil. A Dewar flask in turn surrounded the above, and was partially immersed in liquid air. In operation, sufficient of the sample was placed in the Pyrex tube to cover the thermometer elements but not to exceed the limit of stirrer travel.

A minor modification which resulted in a material increase in precision was made in the design of the motor-driven stirrer. Stirrers customarily have consisted of a wire helix. The helices employed in the present apparatus were formed on a mandrel and rigidly attached thereto. While rotating the mandrel in a lathe, the helix was ground until the wire comprising it had approximately a semicircular cross section, the flat being on the outer side of the helix. This gave the stirrer a sharp shearing edge. It is believed that the increase of 
precision results from the fact that this sharp edge shears microscopic crystals from the walls of the container as soon as they begin to form. Being microscopic, the crystals are rapidly dispersed throughout the liquid, and greatly improve the approach to equilibrium attained during freezing. When a partially frozen sample is removed from this apparatus, it has a milky appearance; as it begins to warm, this milkiness disappears almost instantaneously, indicating very small crystal size.

Boiling points of samples were measured while the samples were being distilled through a 10-inch jacketed column [3], the jacket being externally heated electrically to a temperature such that only slight condensation occurred in the column. A platinum resistance thermometer inserted in the column was used for the temperature measurement. The barometer used for measurement of atmospheric pressure in the determinations on isooctane was a Fuess Standard, readable to $0.01 \mathrm{~mm}$. Reproducibility of results, when corrected to $760 \mathrm{~mm}$ $\mathrm{Hg}$, a veraged better than $0.002^{\circ} \mathrm{C}$, equivalent to $0.04 \mathrm{~mm} \mathrm{Hg}$. An inferior Fortin-type barometer, readable only to $0.1 \mathrm{~mm}$, was used in the determinations on $n$-heptane; although it was calibrated after each measurement by determining the boiling point of water, the reproducibility averaged only $0.009^{\circ} \mathrm{C}$, equivalent to $0.2 \mathrm{~mm} \mathrm{Hg}$.

A Mueller bridge having coils maintained continuously at $35^{\circ} \mathrm{C}$ and reading directly to $0.0001 \mathrm{ohm}$, was used in conjunction with a 25-ohm platinum resistance thermometer on both boiling- and freezing-point tests. Both the bridge and the thermometer were calibrated frequently, the latter in accordance with the procedure specified for the International Temperature Scale.

The refractive indices of the carefully dried isooctane, measured by L. W. Tilton [2] of this Bureau, were determined for sodium light by the minimum-deviation method, using a water-jacketed hollow prism which was mounted in a stirred air bath on the spectrometer table. A platinum resistance thermometer was immersed in the sample during index measurements, and the indices were corrected to refer to dry air at the listed temperatures and at a pressure of 760 $\mathrm{mm} \mathrm{Hg}$. The probable error in determining the indices is less than 0.000005 , and it is thought that the systematic error of the determination did not exceed this value. The indices for $n$-heptane were determined on an Abbe type refractometer (Valentine) graduated to 0.0001 and calibrated against the isooctane.

The densities of the samples, determined by E. L. Peffer of this Bureau, were measured by picnometer. The measured values given for the dry samples are believed to be correct to within \pm 0.00001 .

\section{PHYSICAL PROPERTIES}

The physical properties of isooctane and $n$-heptane found in this investigation are given in table 1, together with the summarized boiling-point data of Smith and Matheson [4], and data from a critical review by Von Grosse and Egloff [5].

It is believed that Smith and Matheson's ebulliometric data on $n$-heptane are decidedly more accurate than those obtained in this investigation. It should be mentioned that their samples were not 
the same as those used herein, and that their apparatus also differed materially.

TABLE 1.-Physical properties of n-heptane and isooctane (2, 2, 4-trimethylpentane)

[For precision of measurements see text]

\begin{tabular}{|c|c|c|c|c|c|c|c|c|c|c|}
\hline \multirow{2}{*}{ Reference 1} & \multirow{2}{*}{$\begin{array}{c}\text { Freezing } \\
\text { point }\end{array}$} & \multirow{2}{*}{$\mid \begin{array}{c}\text { Boiling } \\
\text { point } \\
760 \mathrm{~mm} \\
\mathrm{Hg}\end{array}$} & \multirow{2}{*}{$d t / d P$} & \multicolumn{2}{|c|}{ Refractive index } & \multirow{2}{*}{$d n / d t$} & \multicolumn{2}{|c|}{ Density } & \multirow{2}{*}{$d D / d t$} & \multirow{2}{*}{$\begin{array}{c}\text { Freez- } \\
\text { ing } \\
\text { point } \\
\text { lower- } \\
\text { ing }\end{array}$} \\
\hline & & & & $n_{D}^{20}$ & $n_{D}^{25}$ & & $D^{20}$ & $D^{T}$ & & \\
\hline
\end{tabular}

ISOOCTANE $\left(2,2,4-\mathrm{Me}_{8} \mathrm{PENTANE}\right)$

\begin{tabular}{|c|c|c|c|c|c|c|c|c|c|c|}
\hline $\begin{array}{l}\text { Present work } \\
\text { Smith and Math- } \\
\text { eson [4] }\end{array}$ & ${ }^{\circ} \mathrm{C}$ & $\begin{array}{c}{ }^{\circ} \mathrm{C} \\
99.234 \\
99.234\end{array}$ & $\begin{array}{c}{ }^{\circ} \mathrm{C} \text { per } \\
\mathrm{mm} \mathrm{Hg} \\
0.04651 \\
.04651\end{array}$ & 1.39146 & 1. 38899 & 0.000494 & $\begin{array}{l}\mathrm{g} / \mathrm{ml} \\
0.69182 \\
0\end{array}$ & $\begin{array}{c}g / m l \\
0.68356^{30 \circ}\end{array}$ & $\begin{array}{l}g / m l{ }^{\circ} \mathrm{C} \\
0.000826 \\
-\end{array}$ & $\begin{array}{c}{ }^{\circ} \mathrm{C} \text { per } \\
\text { mole- } \\
\text { percent } \\
0.2381 \\
\end{array}$ \\
\hline $\begin{array}{l}\text { Von Grosse and } \\
\text { Egloff [5] }\end{array}$ & -107.41 & 99.3 & & 1. 3916 & & & .6918 & & .00080 & \\
\hline
\end{tabular}

$n$-HEPTANE

\begin{tabular}{l|c|c|c|c|c|c|c|c|c|c}
\hline $\begin{array}{l}\text { Present work } \\
\text { Smith and Math- } \\
\text { eson [4] }\end{array}$ & -90.576 & 98.422 & 0.04493 & 1.38777 & 1.38523 & 0.000508 & 0.68372 & 0.6794825 & 0.000848 & 0.2004 \\
$\begin{array}{r}\text { Von Grosse and } \\
\text { Egloff [5] }\end{array}$ & -90.62 & 98.38 & .0449 & 1.38774 & $\ldots$ & .00046 & .68365 & .67522300 & .00084 & $\ldots$ \\
\hline
\end{tabular}

1 See reference [5] for a critical review of the literature.

The data on freezing-point depression were obtained on samples of fairly high purity and are plotted in figures 2 and 3 , for isooctane and $n$-heptane, respectively. Freezing curves for the purest samples of isooctane and $n$-heptane are given figures 4 and 5 .

\section{CALCULATION OF PURITY}

From the data in table 1, it follows that if the purity of isooctane is above 97 mole-percent, it can be expressed, relative to that of the present preparation, by the formula

where

$$
P=\frac{131.121+t}{0.2381}
$$

$P=$ mole-percent 2, 2, 4-trimethylpentane

$t=$ observed freezing point, ${ }^{\circ} \mathrm{C}$.

The analogous formula for $n$-heptane is

$$
P=\frac{110.616+t,}{0.2004}
$$

where the symbols have a similar meaning.

The assistance of L. W. Tilton and E. F. Peffer in making the refractive index and density measurements is gratefully acknowledged. It is a pleasure to acknowledge also the great assistance rendered by the members of the American Petroleum Institute Project 6, both in consultation and in permitting use of their distillation apparatus for this work. 


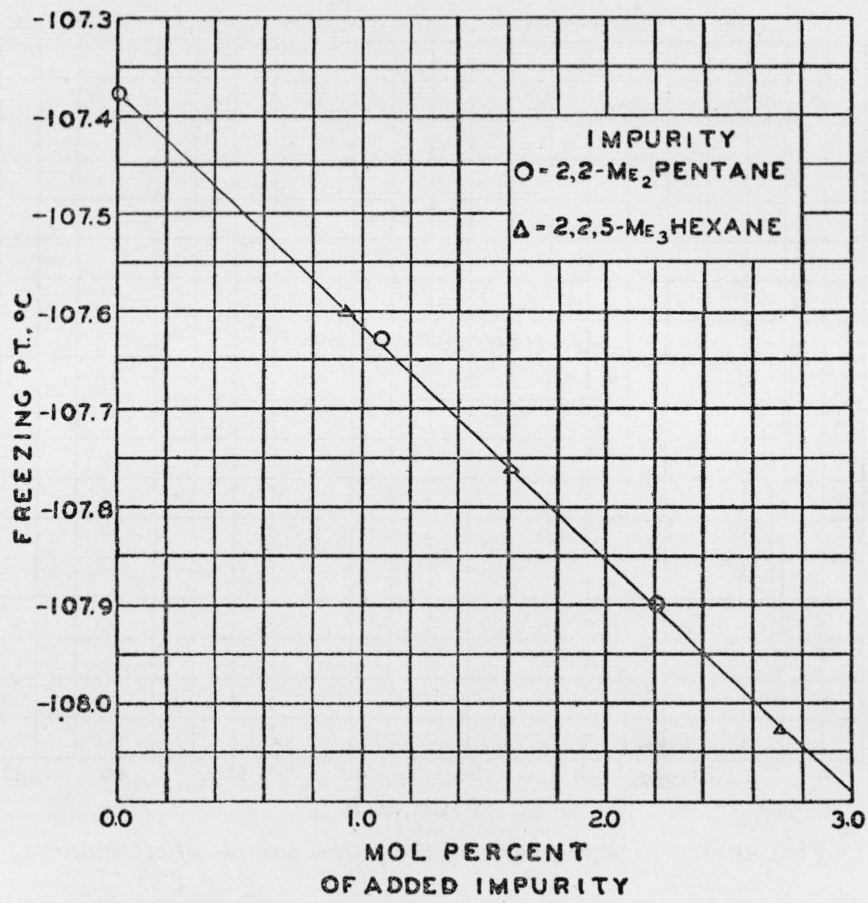

FIGURE 2.-Effect of impurities on the freezing-point of isooctane.

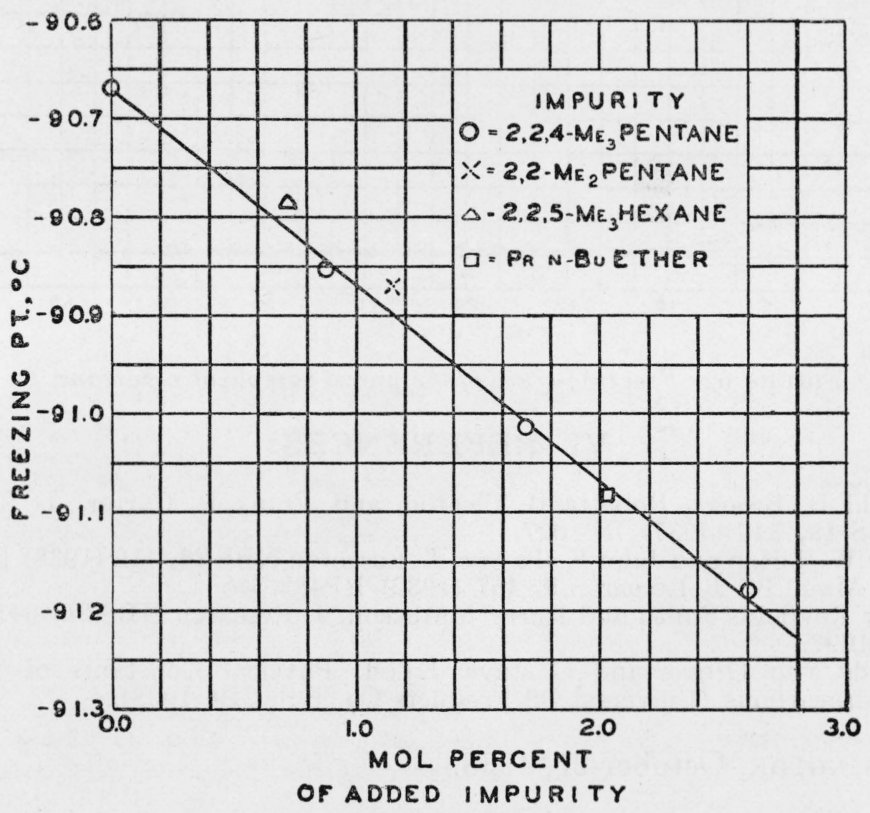

FiguRe 3.-Effect of impurities on the freezing-point of n-heptane. 


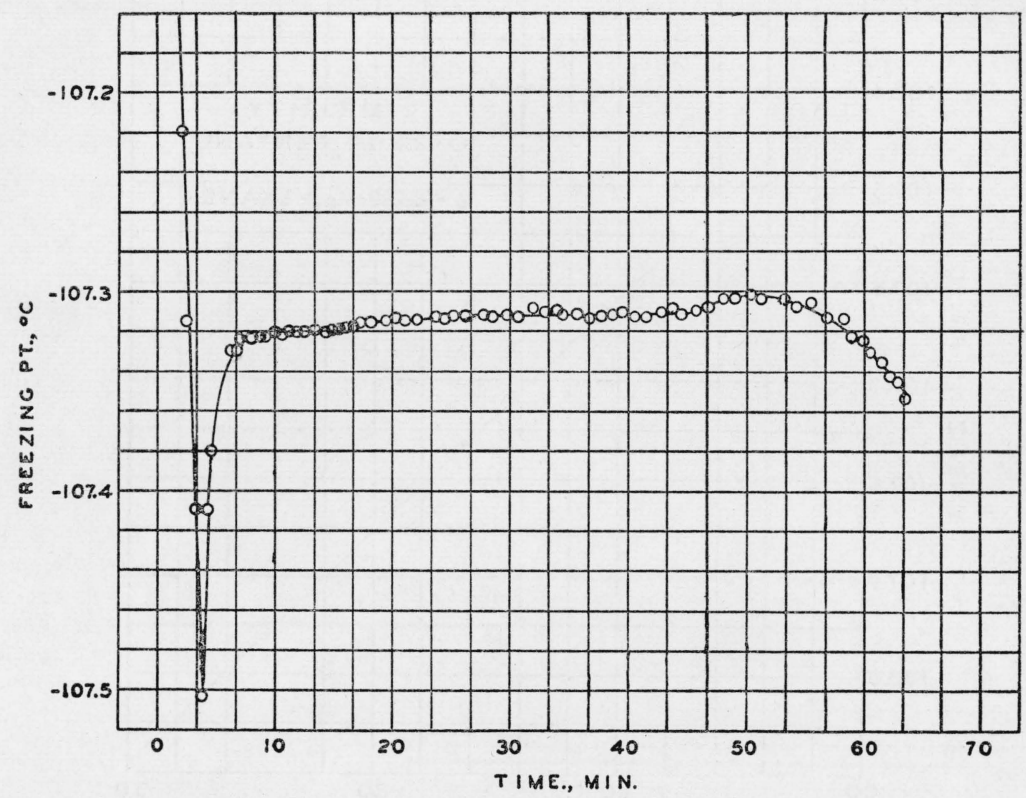

FiguRe 4.-Freezing-curve of the purest sample of isooctane.

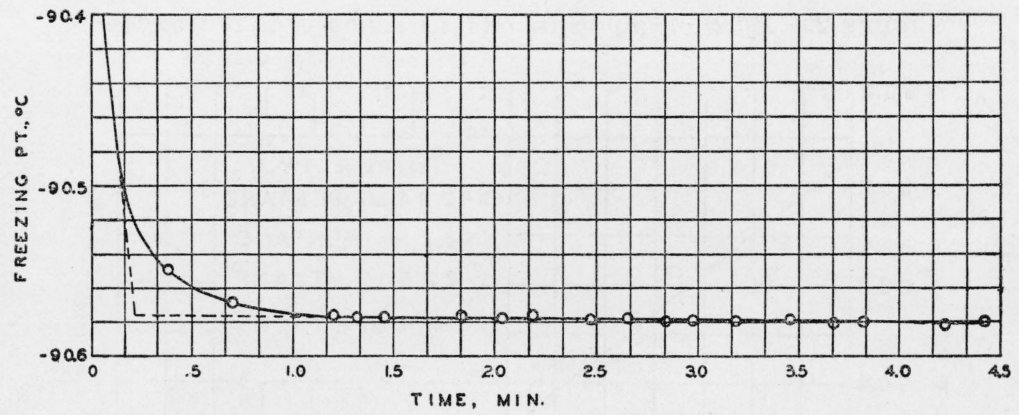

FIGURE 5.-Freezing-curve of the purest sample of n-heptane.

\section{REFERENCES}

[1] Donald B. Brooks, Robetta B. Cleaton, and Frank R. Carter, J. Research NBS 19, 319 (1937) RP1027.

[2] Leroy W. Tilton and John K. Taylor, J. Research NBS 20, 419 (1938) RP1085.

[3] B. J. Mair, BS J. Research 9, 457 (1932) RP482.

[4] Edgar Reynolds Smith and Harry Matheson, J. Research NBS 20, 641 (1938) RP1097.

[5] Aristide von Grosse and Gustave Egloff, Physical Constants of Paraffin Hydrocarbons (Universal Oil Products Co. Bul. 219, 1938).

Washington, October 27, 1938. 